\title{
O R I G I N A L RESEARCH \\ Retaining older experienced nurses in the Northern Territory of Australia: a qualitative study exploring opportunities for post-retirement contributions
}

\author{
K Voit ${ }^{1}$, DB Carson ${ }^{2}$ \\ ${ }^{1}$ Charles Darwin University, The Northern Institute, Darwin, Northern Territory, Australia \\ ${ }^{2}$ Flinders University, Adelaide, South Australia, Australia
}

Submitted: 2 August 2011; Revised: 30 November 2011; Published: 19 April 2012

\section{Voit K, Carson DB}

Retaining older experienced nurses in the Northern Territory of Australia: a qualitative study exploring opportunities for post-retirement contributions

Rural and Remote Health 12: 1881. (Online) 2012

Available: http://www.rrh.org.au

\section{A B S T R A C T}

Introduction: Many countries are facing an ageing of the nursing workforce and increasing workforce shortages. This trend is due to members of the 'baby boomer' generation leaving the workforce for retirement and a declining pool of younger people entering the nursing profession. New approaches to engaging older nurses in the workforce are becoming common in nursing globally but have yet to be adapted to remote contexts such as the Northern Territory (NT) of Australia. This article reports findings from a qualitative study of 15 participants who explored perceived opportunities for and barriers to implementing flexible strategies to engage older nurses in the NT workforce after they resign from full-time work.

Methods: The study used a descriptive qualitative design. Data were collected using semi-structured interviews with NT nurses approaching retirement (six nurses aged 50 years and over) and their managers $(n=9)$. Clinicians were employed in practice settings that included hospitals, community health and 'Top End' (north of and including the town of Katherine), as well as Central Australian remote area communities. One participant who was employed as primary health centre manager in a remote community also held a clinical role. Managers were employed in both senior and line management positions in community and remote health as well as NT hospitals.

Results: Three major themes emerged from the data. First, interview participants identified potential for flexible post-retirement engagement of older nurses and a range of concrete engagement opportunities 'on and off the floor' were identified. Second, the 
main barriers to post-retirement engagement were an existing focus on the recruitment of younger Australian and overseas-trained nurses, and the remoteness of nursing practice settings from the residential locations of retired nurses. Third, existing informal system of post-retirement working arrangements, characterized by ad hoc agreements between individual nurses and managers, is poorly suited to scaling up.

Conclusion: A knowledge and change-management approach is required to change employers' views of the value of older nurses. Better engagement of those nurses may assist the NT Department of Health address the severe nursing workforce shortages and prevent the loss of significant remote area nursing knowledge.

Key words: Australia, change management, knowledge management, Northern Territory, nursing shortage, retention, workforce ageing, workforce planning.

\section{Introduction}

As in many other countries, Australia's Northern Territory (NT) is facing the ageing of the nursing workforce and increasing workforce shortages. Past strategies for addressing workforce shortages in the NT have focused almost exclusively on the recruitment of a declining (in relative terms) pool of young nurses from elsewhere in Australia and, more recently, from overseas. Strategies for engaging older workers, and particularly those withdrawing from full-time work, have been employed in other places as a response to workforce shortages but have yet to be actively pursued in the NT.

The purpose of this research was to identify the opportunities for and barriers to implementing strategies to continue the engagement of older nurses nearing retirement in the NT workforce. The research involved qualitative interviews with key informants from the nursing workforce and health system, and this article addresses retention strategies, knowledge management and change management processes.

\section{Literature review}

Nursing workforce ageing: Recent studies have emphasized an increasing demand for nurses in developed nations such as Australia. This trend is due to an ageing population, decreasing numbers of people entering the nursing profession and the ageing of the nursing workforce ${ }^{1}$.
Consequently, there is a strong need for creating workforce models that make best use of available workers in a shrinking workforce pool ${ }^{2}$.

At the turn of the century, research from the USA reported that a large cohort of the baby boomer generation of registered nurses $(\mathrm{RNs})$ was expected to reach retirement by $2010^{3}$. The National Center for Health Workforce Analysis predicted that the USA would face a $31 \%$ staffing shortage by $2020^{4}$. More recent research argued that the expected workforce shortages have been realised, and that strategies to improve the continuing engagement of older (particularly baby boomer generation) nurses have become an essential part of workforce planning in education as well as practice settings ${ }^{5,6}$.

The situation in Canada is similar, with a study by the Canadian Institute for Health Information ${ }^{7}$ identifying that $19.7 \%$ of the total Canadian nursing workforce is aged 55 years or older. With an average retirement age of 55 to 58 years for Canadian nurses ${ }^{8}$, many of these nurses have left or are now leaving the profession for retirement. The Canadian Nurse Association reports that over 24\% of the workforce was eligible for retirement in 2007 resulting in a predicted national shortfall of 78000 RNs by $2011^{9}$.

Many countries have responded to expected workforce shortages by increasing the number of places in nursing preservice education programs and marketing nursing as a career option to prospective students. The UK has trained 5500 
more nurses every year since 2004. Ireland increased its number of places for nursing students from 968 in 1998 to 1640 in 2002, and Canada and a number of American states have used similar strategies ${ }^{1}$.

In Australia, Karmel predicted a shortage of 40000 nurses by the year $2010^{10}$. The Australian Health Workforce Institute estimated that up to 90000 Australian nurses would be retiring by 2020, with a greatly reduced inflow of new recruits ${ }^{11}$. The National Health Workforce Taskforce urged immediate and substantial changes to workforce management and development strategies in an attempt to deal with the increasing shortage of nurses and other health professionals ${ }^{2}$.

The specific NT context is an unusual setting for nursing practice, even within Australia. The very small population (approximately 220000 people in 2010) includes a substantial number of Indigenous people $30 \%$ of the total population), many of whom live in remote and very remote locations. Remoteness and the challenges of working with Indigenous populations have long been cited as reasons for existing nursing workforce shortages in the $\mathrm{NT}^{12}$.

The small local population and isolation from major educational institutions in remote areas has meant the NT nursing workforce is largely recruited from outside the jurisdiction, with attendant high staff turnover. Approximately $26 \%$ of the total nursing workforce moves in or out of the NT each year ${ }^{13}$ and a sizable proportion of the workforce is seasonal or migratory, maintaining their primary residence outside NT. This 'expatriate' group of nurses is substantially older than new recruits who live and work within the $\mathrm{NT}^{14}$.

There is also a large group of long-term resident nurses, many of whom moved to the NT during the 1970s and 1980s and are now nearing retirement age. Evidence suggests that many of these nurses will leave the NT once they cease fulltime work, with very few likely to remain in remote Indigenous communities ${ }^{15}$. The older, long staying nurses have served in the NT during most of their careers and gained a substantial body of knowledge in remote area nursing. The current recruitment system replaces older retiring nurses with very young (in their first or second job) nurses with limited remote area experience. This results in a workforce polarised in terms of age and experience. Managing such a split workforce and retaining the knowledge-base of older nurses are critical tasks for the health system ${ }^{14}$.

A consequence of the bimodal age distribution of the NT nursing workforce is an age 'crater" ${ }^{16}$ of mid-career nurses which, in part, arises from fewer nurses returning to practice in the NT after having children than is the case elsewhere. These nurses either withdraw from the workforce or migrate from the NT to raise their families elsewhere. The issues associated with transferring knowledge from the older to the younger nursing generation are especially acute in the NT because there are relatively few nurses in the 'middle ages' who can act as generational brokers between older and younger workers.

Geographical circumstances further distinguish the NT from urban and even other remote jurisdictions. Adding to isolation challenges and unusual demographics in both patient population and the nursing profession is the substantial number of younger overseas-trained nurses who are mostly unfamiliar with remote community nursing conditions ${ }^{14}$. Despite the observation that overseas trained nurses struggle to adapt to language issues (recognising that many Indigenous people do not have English as a first language) and the need to work independently in small and isolated work settings ${ }^{14}$, the recruitment of such nurses continues to be a major focus for the NT Department of Health to compensate for the shortage of available Australian trained young nurses.

\section{Strategies for the retention and management of} older nurses: The issues of workforce ageing and workforce shortages are a common concern, regardless of employment sector $^{17}$. Businesses in the USA are developing strategies for recruiting, engaging, motivating and retaining older workers as a method to sustain their workforces ${ }^{18}$. Several surveys conducted in the USA have suggested that a larger proportion of the current generation of older workers (aged $\geq 50$ years) intends to work beyond official retirement than in previous 
generations. For instance Mermin et al found that 38\% of older workers want to phase gradually into retirement rather than abruptly leaving the workforce ${ }^{19}$. The challenge for employers is to find meaningful ways to continue to engage older workers and retain their knowledge and skills while allowing more flexible modes of working than in the past.

Implementing workforce strategies that target older workers is not a straightforward task. Older employees are often viewed as less valuable than those younger ${ }^{20}$, and consequently recruitment and retention strategies tend to be overly focused on the young ${ }^{21}$. Organisations that have succeeded in engaging workers aged 50 years and older tend to be either those located in areas where there has been substantial out-migration of younger people ${ }^{22}$, or where the business culture values retention and recruitment at least equally $^{23}$. A recent survey of the nursing workforce noted that neither of these conditions were apparent in the $\mathrm{NT}^{14}$. There was substantial in-migration of younger nurses (who then left in mid-career), and employers were much more concerned about recruiting these nurses than the retention of older nurses.

Human resources management strategies are central to efforts to retain older workers ${ }^{22}$. Human resources systems must be able to cope with flexible working options, training and development programs, job re-design, recognition strategies as well as attractive compensation options targeting older workers. The 'working retired' will be looking for challenging assignments, new roles such as mentoring and reduced job demands ${ }^{22}$. The need for flexible and individualised work arrangements can result in ad hoc agreements between management and selected workers, but as the pool of older workers grows, informal systems become more difficult to manage, and formal systems need to be developed and implemented ${ }^{18}$.

Research from the USA suggests that administrators of hospitals and nursing homes are aware of the issue of an ageing workforce, and many of the organisations studied indicated an intention to retain older nurses ${ }^{24}$. However, $94 \%$ of those organisations had no policies in place to promote the retention of nurses approaching retirement and $87 \%$ had no plans to create policies or human resource strategies to address the needs of older nurses.

Another US study recommended retaining rural and remote nurses especially via the creation of 'employee benefit groups' for nurses 59 years and older, including pro-rated benefits, flexible hours, ongoing professional education, preceptorship models, phased retirement and other options that might appeal to older nurses in rural and remote settings ${ }^{25}$. However, many of the incentives introduced focused on nurses in large acute-care settings where nursing shortages are predicted to have the greatest impact ${ }^{25}$. With few exceptions, little attention has been paid to the characteristics of the rural or remote nursing workforce and there is a strong need to foster the implementation of ageing workforce strategies tailored particularly to remote settings ${ }^{25}$.

Remote settings already experience difficulties in recruiting and retaining skilled staff. They are also less likely than urban and rural settings to have semi-retired or fully retired nurses living locally. This implies spatial challenges: how to attract older nurses to remote areas to work in different ways (shorter hours, job sharing, flexible hours etc) than have been the norm to date. Consideration also needs to be given to systems that allow nurses in situ to access to the knowledge and expertise of older nurses who have moved away.

Valuing older nurses - a knowledge and change management approach: The cost of lost knowledge is difficult to quantify and many organizations face challenges in identifying where they are most vulnerable in terms of knowledge loss ${ }^{17}$. Knowledge management strategies have been developed to help organisations identify what knowledge exists and to create mechanisms through which knowledge can be retained and shared. Knowledge management strategies offer potential to assist workplaces in retaining at least some of an older nurse's acquired expertise $^{26}$. Much of the key knowledge in the nursing profession is based on experience and tacit understandings, 
and codifying tacit knowledge is a major challenge to an organisation $^{27}$.

In the context of nursing, it has been suggested that a focus on the demands of clinical work and relatively inflexible work conditions not only makes it more difficult for older nurses to continue to engage in the workforce, but also more difficult for them to be involved in knowledge management programs ${ }^{17}$. While various knowledge management strategies have been proposed, such as mentoring or preceptor systems $^{17}$, the unwillingness or inability of workplaces to change attitudes towards the tasks and staff that are valued remains a substantial barrier to implementation.

Following Kurt Lewin's model of change management ${ }^{28}$, in the NT there is a need to both identify the driving forces for organisational change - the impending outflow of both human and knowledge resources from the NT workforce; and the barriers to implementing change - the entrenched work practices and attitudes of senior managers.

\section{Methods}

\section{Design}

This study used a descriptive qualitative design. Data were collected in September and October 2009 using qualitative semi-structured interviews with nurses and their managers. Participants for the study were recruited by email. An information sheet and invitation letter was sent to all public hospitals and health services in the NT. Targeted participants for interviews were nurses aged 50 years and older and their managers. Those nurses and managers who expressed interest in the research were contacted to arrange an interview. Informed consent was obtained from all participants prior to the interview. In total, 15 people volunteered to participate in the study, and all interview participants held current nurse $(n=6)$ or nurse manager $(n=9)$ positions in the NT (Table 1$)$.

\section{Data collection}

Conducted interviews were of $30 \mathrm{~min}$ to one hour duration and were audiotaped to assist with data analysis. Field notes were taken during all interviews. Interviews with nurses included questions about their intentions after nursing life and the contribution they could see themselves making to NT nursing once they retired from full-time work. Interview participants were also asked if they could think of incentives that would attract them to stay in the NT after retirement from both a personal and a professional perspective. Interviews concluded by asking nurses about the structural changes they thought might be needed to allow them to continue to contribute to the profession.

Interviews with nurse managers included questions about their experience in managing an ageing workforce and the retention of older staff. Participants were asked about their existing knowledge management strategies (formal and informal), and particularly how tacit knowledge is managed. Managers were also asked about any opportunities they thought existed for engaging older nurses in the NT workforce. Nursing managers were also encouraged to talk about their own retirement intentions and whether they could imagine themselves continuing to engage in the NT workforce following retirement from full-time work.

\section{Data analysis}

To categorize critical themes emerging from the gathered data, taped interviews were transcribed and thoroughly reviewed. Data analysis commenced during the data collection and transcribing process, in order to discuss emerging themes further with other respondents. Analysis was conducted using an open coding approach. Hughes and Hayhoe argue that this approach codes data directly from the interview transcripts, also known as 'in vivo coding ${ }^{29}$. Codes were grouped and categorised to identify common themes from the collected data. Patterns appearing from this analysis were classified and collated under the subheadings in the results section below. 


\section{Table 1: Interview participants' designation and practice context}

\begin{tabular}{|l|c|c|c|}
\hline \multirow{2}{*}{ Context } & \multirow{2}{*}{ Nurses } & \multicolumn{2}{|c|}{ Managers } \\
\cline { 3 - 4 } & & Line manager & $\begin{array}{c}\text { Senior } \\
\text { manager }\end{array}$ \\
\hline NT Hospitals & 3 & 3 & 1 \\
\hline Community health & 2 & 1 & 2 \\
\hline Remote health & 1 & 1 & 1 \\
\hline Total & 6 & 5 & 4 \\
\hline
\end{tabular}

NT, Northern Territory.

\section{Ethical considerations}

Ethics clearance was obtained from Charles Darwin University Human Research Ethics Committee (H09037) prior to study commencement.

\section{Results}

\section{Post-retirement engagement: levels of enthusiasm among Northern Territory nurses}

Nurse participants unanimously wished to continue productive paid work once they formally retired from their current full-time positions. They also acknowledged that other life duties such as family responsibilities and pursuing hobbies and outside interests would take up more of their time. Not all participants planned to live in the NT full time once they retired, but they did have plans to travel and could envisage spending at least part of the year in the NT.

I want to do part time work because nursing is something you have been doing all your life and suddenly you won't be doing it and you don't want to leave it cold turkey you might want to gradually get out of it. (Nurse, Interview 6)

A lot of people I talked to talk about doing a little bit of part time work. Some nurses think about reducing to part-time towards approaching their retirement age and then continue with part-time after retiring. (Nursing Director, Interview 5)
Working arrangements that appealed to participants varied in terms of fields of nursing as well as working schedules. Nurses mentioned that engaging after retirement would help them keep their standard of living because some stated they could not afford to retire at this stage. At the same time, fulltime work was mostly not an option for participants.

Concrete possibilities for casual work were seen in part-year engagements, short-term placements, cycling in and out of the workforce, job sharing or job rotation. These options could be consolidated in a casual pool of older staff.

\section{'On and off the floor'}

There appeared to be two main ways nurses could imagine contributing to the profession once they cease full-time work: post-retirement nursing 'on and off the floor'. While post-retirement engagement 'on the floor' refers to nursing practice itself, opportunities for post-retirement engagement 'off the floor' included mentoring and buddy systems for younger and overseas-trained nurses, storytelling, voluntary phone support systems in remote areas, and engaging in terminated projects (ie projects with clear parameters, timeframes, and endpoints).

Older nurses could also imagine engaging in handing over jobs to the younger generation of nurses and interviewing other retirees about their specific remote area nursing knowledge. One recommendation was for a research position to be established within the hospital or the Department of Health. Other engagement strategies included having retired 
nurses act as 'Territory representatives' helping promote NT jobs to prospective staff, and engaging newly retired nurses in developing a range of policies.

I would like to, when I do retire from my full-time position, be able to do some casual work. And also I'm looking at volunteer work as well. It would be good if I could job share. (Nurse, Interview 9)

I could imagine going back and do a shift or two at the hospital if that was available, I could keep my skills up within that time. (Nurse, Interview 12)

\section{Incentives for continuing engagement}

Participants felt that they were not acknowledged for their years of expertise, and this impacted on their willingness to enter the post-retirement workforce. Participants identified several incentives which would help them continue engagement in the NT workforce after formal retirement. Skill refresher courses were desired, and the coverage of nurse's annual registration fee was mentioned as key incentive for retention. Providing nurses with airfares to enable visits to relatives interstate and assistance with affordable accommodation, especially if nurses wish to come back to the NT for periods of time, were other major retention strategies identified. Interview participants raised concerns about adequate access to health care, and the availability of services for nurses like themselves were seen as vital. However, most nurses assessed their health status as good and felt they would be able to provide care with a reduced workload. Many nurses leave the NT for the time of their retirement and attractive strategies for flexible engagement need to be offered before nurses leave the NT to retire elsewhere.

\section{The need for a formal post-retirement engagement framework}

Offering a formal engagement framework could influence nurses' decision to stay. Interview participants recognized the lack of formal options relating to flexible post-retirement engagement which was seen as a barrier to having policies that work across the spectrum of employment. Employers need to develop formal engagement packages that are offered to nurses before they reach the transition to retirement.

I could imagine engaging in mentoring or assisting in the attraction of new nurses but I wouldn't imagine that those positions are open. I have never seen anything like that open to nurses. (Clinical Nurse Consultant, Interview 4)

I have always been an active person and I cannot see myself not doing anything. I don't wish to just sit and retire. Options haven't been offered to me. In the 20 years I've been here it hasn't happened before. (Nurse, Interview 9)

Line managers had observed substantial out-migration of younger nurses to other states. It was perceived that the limited types of nursing jobs available in the NT compared with other parts of the country worsened existing recruitment and retention difficulties. Line managers identified opportunities for the continuing engagement of older nurses. These included flexible working hours and training opportunities targeted towards the needs of older nurses, creative job design options, a compensation scheme, as well as recognition and acknowledgement strategies that would need to be developed. Sufficient health services for employees and improved public transport systems, as well as the availability of a retirement village were key requirements for retention. It was, however, acknowledged that strategies aiming to meet the needs of older workers and engage them after ceasing full-time work have not yet been discussed at a governmental level.

Especially in times of severe shortages of staff, there has to be flexibility in re-employing them. Unfortunately, people don't think of older nurses, they are not the first option. They just look for people interstate and overseas. If they would offer retirees working one day a week they might be able to backfill. (Line Manager, Interview 1) 


\section{Facilitating workforce retention}

It was acknowledged that there were no formal strategies in place to keep remote area knowledge within the profession. One suggestion was for a 'retired nurses' network' which could coordinate strategy development. Such a network would require corporate or government sponsorship. This research also identified the need for a driver, a person or persons to take responsibility for establishing a network, and line managers suggested that a half-time position could be created for this. The network would help identify engagement opportunities in specific departments and communicate these opportunities to older nurses, as well as offering training and professional updates for interested nurses. Additionally, the managers suggested the creation of a Facebook page to communicate vacant positions and to set up network meetings. The creation of a newsletter within the network and professional supervision were also recommended.

Currently at the moment there are quite a few nurses who have retired and get together once every few weeks at each other's houses and some of the people closer to retirement age go to those meetings. That is already in place but it's not formal per se. Today you would have to do it on the net. Something is needed that gets people thinking and talking. (Nurse, Interview 13)

\section{Discussion}

This research identified the perceived benefits of the continuing engagement of older nurses according to the participating 6 nurses (aged $\geq 50$ years) and 9 managers. The participants came from a range of practice and management contexts, and engagement opportunities were identified not just in the area of direct nursing practice, but also in mentoring, management, policy development, and even recruitment and training activities that can take place outside of the NT. The perceived opportunities for engaging older nurses in a more flexible NT workforce are consistent with the emerging literature on post-retirement labour.
The research reinforced the observations of Lenthall et al that the NT context presents specific barriers and challenges to the engagement of older nurses when compared with other jurisdictions in which similar work has been conducted ${ }^{30}$. Most prominent of these is the challenge of remoteness. Strategies such as job sharing would be difficult to arrange in remote NT communities due to the costs and logistical issues involved in providing suitable accommodation. The physical demands of nursing work and the need for being on-call in remote communities pose further challenges to the engagement of older nurses, particularly in part-time arrangements. The nature of on-call work means that nurses are often required to work well beyond normal working hours and restricting the hours of work to part time would be difficult. While remote environments lend themselves to the mobile workforces appropriate for seasonal backfilling of positions, the challenge is to introduce flexible work arrangements that better align with the on-call nature of remote area nursing work and the physical demands of the profession (ie engaging older nurses in mentoring full-time, recently qualified remote area nurses).

There is a strong need for a knowledge and change management approach to addressing the issue of retaining older nurses in the active workforce. While increasing flexibility is becoming common in the nursing workforce globally, this research supports Simons et al's observations ${ }^{1}$ that remote places such as the NT have lagged behind due to a continuing need to address workforce shortages through the recruitment of full-time, young, recently qualified nurses. What new and flexible strategies might do, however, is to open up the NT workforce to new groups (eg older nurses, working mothers, fly-in/fly-out workers) and so increase the pool of potential staff.

\section{Conclusion}

Important insight into opportunities for, and barriers to, post-retirement engagement strategies was gained from a small sample of 15 NT nurses and their managers. Current nursing shortages have been extensively researched and 
declared a major priority in policy and practice settings worldwide. While the opinions of participating nurse managers were consistent with international literature on current nursing shortages, the findings from this research suggest that little consideration has been given to implementing flexible strategies to alleviate current staffing shortfalls by engaging older nurses post-retirement.

Despite Bittman et al's observation that older workers are viewed as less valuable ${ }^{20}$, this research identified interest among managers in engaging older nurses post-retirement. This could reflect the nature of the small sample, or it could indicate that the issues involved are more complex than has previously been believed. Building on previous calls for increased awareness of continuing engagement strategies for older nurses globally ${ }^{5}$, the present research suggests the need for greater attention to implementing knowledge and change management approaches in the NT to open the workforce to the engagement of older nurses approaching retirement.

\section{References}

1. Simons S, Villeneuve M, Hurst J. Tackling Nurse Shortages in OECD Countries. OECD health working paper. Paris: OECD, 2005.

2. National Health Workforce Taskforce. Health Workforce in Australia and Factors for Current Shortages. Canberra, ACT: National Health Workforce Taskforce, 2009.

3. Minnick A. Retirement, the Nursing Workforce, and the Year 2005. Nursing Outlook 2000; (48): 211-217.

4. National Center for Health Workforce Analysis. Projected supply, demand and shortages of registered nurses: 2000-2020. Washington, DC: US Department of Health and Human Services, 2002.

5. Fox RL, Abrahamson K. A Critical Examination of the U.S. Nursing Shortage: Contributing Factors, Public Policy Implications. Nursing Forum 2009; 44(4): 235-244.
6. Roehrs CJ. Getting Started: Needs and Preferences of Colorado Faculty for Graduate Education in Nursing. Nursing Education Perspectives 2011; 32(2): 84-88.

7. Canadian Institute for Health Information. Workforce Trends of Registered Nurses in Canada, 2004. Ottawa, ON: CIHI, 2005.

8. Baumann A, O'Brien-Pallas L. The Status of the Nursing Workforce in Ontario: The Numbers and the Worklife Issues in November 2001. Ottawa, ON: Canadian Nurses' Association, 2001.

9. Canadian Nurse Association. Unions and Ontario Nurses' Association. (Online) 2005. Available: http://www.ona.org/faqs. html (Accessed 31 May 2011).

10. Karmel T, Li J. The Nursing Workforce 2010. Canberra, ACT: Department of Education and Science and Training, 2002.

11. Australian Health Workforce Institute. Review of the Nursing Workforce in Australia. Melbourne, VIC: Australian Health Workforce Institute, 2008.

12. Weymouth S, Davey C, Wright JI, Nieuwoldt L, Barclay L, Belton $\mathrm{S}$ et al. What are the effects of distance management on the retention of remote area nurses in Australia? Rural and Remote Health 7: 652. (Online) 2007. Available: www.rrh.org.au (Accessed 28 May 2011).

13. Department of Health. Total Nursing and Midwifery Trends 2005 to 2011. Darwin, NT: Department of Health, 2011.

14. Garnett ST, Coe K, Golebiowska K, Walsh H, Zander KK, Guthridge S et al. Attracting and Keeping Nursing Professionals in an Environment of Chronic Labour Shortage: A Study of Mobility among Nurses and Midwives in the Northern Territory of Australia. Darwin, NT: Charles Darwin University, 2008.

15. Martel C. Spatial patterns of older people migrating to and from the Northern Territory. Research Brief. (Online) 2010. Available: http:// www.cdu.edu.au/thenortherninstitute/ (Accessed 28 May 2011). 
16. Martel C, Carson D, Lundholm E, Muller D. Bubbles and Craters: Analysing Ageing Patterns of Remote Area Populations. In: D Carson, R Rasmussen, P Ensign, L Huskey, A Taylor. Demography at the Edge: Remote human populations in developed nations. London: Ashgate, 2011; 107-124.

17. Hatcher BJ, Bleich MR, Connolly C, Davis K, O'Neill H, Hewlett P, Stokley Hill K. Wisdom at Work: The Importance of the Older and Experienced Nurse in the Workplace. Princeton, NJ: Robert Wood Johnson Foundation, 2006.

18. Dychtwald K, Baxter D. Capitalizing on the New Mature Workforce. Public Personal Management 2007; 36(4): 325-334.

19. Mermin GBT, Johnson RW, Murphy DP. Why do boomers plan to work longer? Journal of Gerontology 2007; 62B(5): 286-294.

20. Bittman M, Flick M, Rice J. The Recruitment of Older Australian Workers: A Survey of Employers in a High Growth Industry. Sydney, NSW: Social Policy Research Centre, University of New South Wales, 2001.

21. Business Work Aging. Attracting and retaining older workers in the human services sector: A literature review. Melbourne, VIC: Business Work Ageing, 2005.

22. Armstrong-Stassen M. Organisational practices and the postretirement employment experience of older workers. Human Resource Management Journal 2008; 18(1): 36-53.
23. Andrews J, Manthorpe J, Watson R. Employment transitions for older nurses: a qualitative study. Journal of Advanced Nursing 2005; 51(3): 298-306.

24. Letvak S. Retaining the Older Nurse. Journal of Nursing Administration 2002; 32(7/8): 387- 392.

25. Office of Rural Health \& Primary Care. Retaining Rural Nurses. Midwestern Summit on Retaining and Making Best Use of the Older More Experienced Rural Registered Nurse. St Paul, MN: Minnesota Department of Health, 2007.

26. Christensen Hold P. Knowledge management - perspectives and pitfalls. Kopenhagen: Business School, 2003.

27. Nonaka I. Knowledge Management. Critical Perspectives on Business and Management. New York: Routledge, 2005.

28. Lewin K. Frontiers in group dynamics. Human Relations 1947; 1(2): 143-153.

29. Hughes MA, Hayhoe GF. A Research Primer for Technical Communication: Methods, Exemplares and Analysis. New York: Taylor \& Francis, 2008.

30. Lenthall S, Wakerman J, Opie T, Dunn S, MacLeod M, Dollard $\mathrm{M}$ et al. Nursing workforce in very remote Australia, characteristics and key issues. Australian Journal of Rural Health 2011; 19: 32-37. 